\title{
Biochemical Studies on Methylglyoxal-Mediated Glycated Histones: Implications for Presence of Serum Antibodies against the Glycated Histones in Patients with Type 1 Diabetes Mellitus
}

\author{
Nadeem A. Ansari ${ }^{1,2}$ and Debabrata Dash ${ }^{1}$ \\ ${ }^{1}$ Department of Biochemistry, Institute of Medical Sciences, Banaras Hindu University, Varanasi 221005, India \\ ${ }^{2}$ Department of Biochemistry, Universal College of Medical Sciences, Paklihawa Campus, Bhairawaha, Nepal
}

Correspondence should be addressed to Nadeem A. Ansari; anadeem1@rediffmail.com

Received 17 June 2013; Accepted 17 July 2013

Academic Editors: K.-i. Isobe and J. Neira

Copyright (C) 2013 N. A. Ansari and D. Dash. This is an open access article distributed under the Creative Commons Attribution License, which permits unrestricted use, distribution, and reproduction in any medium, provided the original work is properly cited.

Reactive carbonyl species (RCS) mainly reacts with lysine and arginine residues of proteins to form advanced glycation end products (AGEs). Histone was glycoxidated with glyoxal and methylglyoxal. It was characterized by polyacrylamide gel electrophoresis and quenching studies involving penicillamine and aminoguanidine as carbonyl scavengers. Further characterization of histone modified with methylglyoxal was done by UV, fluorescence, and IR spectrophotometry. Spectral analysis of the protein clearly demonstrates structural perturbation in the histone by methylglyoxal. Methylglyoxal-induces cross-linking in the protein leading to aggregation. Role of methylglyoxal mediated glycoxidation of histone in type 1 diabetes was also undertaken. Antibodies were detected against glycoxidated histone in sera of type 1 diabetes patients by solid-phase enzyme immunoassay. The findings indicate that as a result of structural perturbation in histone by methylglyoxal, the modified histone may be involved in production of serum antibodies in the diabetes patients.

\section{Introduction}

There is overwhelming evidence for involvement of reactive oxygen species (ROS) in a number of pathophysiological conditions such as diabetes, cancer, and aging but the studies linking reactive carbonyl species (RCS) to the conditions are limited $[1,2]$. RCS, such as methylglyoxal, is produced by degradation of lipid peroxidation products, early protein glycation adducts, and as a byproduct of glycolysis. RCS modification of histone results in cross-linking of proteins and induces ROS-dependent cleavage of plasmid DNA [3]. The proteasome degradation of RCS products is not complete and remnants may accumulate and cause epigenetic changes as well as further DNA and protein damage [4]. Earlier studies have shown that histones from liver cells of diabetic rats contain high level of AGEs [5]. We [6] have found antigenicity of glycated poly-L-lysine in experimental animals and autoantibodies were also detected against the modified lysine polypeptide in diabetes patients. A recent work has demonstrated in vivo formation of RCS-mediated AGEs in histone $\mathrm{H}_{1}$ using antibodies against oxidative protein adducts [7]. This study characterizes methylglyoxal-modified histone (a lysine-rich protein) and evaluates its role in type 1 diabetes patients.

\section{Materials and Methods}

2.1. Chemicals. Calf thymus whole histones (type II-A) and methylglyoxal were purchased from Sigma (St. Louis, MO, USA). Polystyrene flat bottom UV microtiter plates were obtained from Greiner BioOne (Germany). All other chemicals and reagents used in the study were of the highest analytical grade.

2.2. Serum Samples. Serum samples of various type 1 diabetes patients proven with diagnostic tests were obtained from Sir Sunderlal Hospital, IMS, BHU, Varanasi, India. These 
samples were routine determinations and were not specifically obtained for the study. Serum samples from normal healthy subjects who gave prior informed consent were used as control. The study has been approved by the ethics committee.

All serum samples were decomplemented at $56^{\circ} \mathrm{C}$ for 30 min before use.

2.3. Preparation of Methylglyoxal-Modified Histone. Histone was glycoxidated as described earlier with minor modifications $[3,8]$. Briefly, histone $(1 \mathrm{mg} / \mathrm{mL})$ in phosphate-buffered saline (PBS, $\mathrm{pH}$ 7.4) was modified by separate incubation with glyoxal (1 and $2 \mathrm{mM}$ ) and methylglyoxal (1 and $2 \mathrm{mM})$ in $0.25 \mathrm{M}$ sodium phosphate buffer, $\mathrm{pH} 7.4$, at $37^{\circ} \mathrm{C}$ for $24 \mathrm{~h}$. Unmodified histone dissolved in the same buffer served as control. Low concentration of RCS is taken as it binds preferentially to lysine and arginine-rich histones and rapidly forms dimers and polymers [9].

2.4. Effect of Carbonyl Scavengers on Methylglyoxal-Modified Histone. Effect of scavengers on RCS modification of histones was determined by addition of coincubated mixtures of penicillamine/aminoguanidine with methylglyoxal or glyoxal to histones and incubation of the reaction mixture at $37^{\circ} \mathrm{C}$ for $24 \mathrm{hr}$. At the end of incubation, fluorescence of the assay mixture was read after excitation at $320 \mathrm{~nm}$ and percent quenching was calculated.

2.5. Polyacrylamide Gel Electrophoresis. Methylglyoxalinduced alteration in histone was examined by sodium dodecyl sulfate polyacrylamide gel electrophoresis (SDSPAGE) as described previously on $15 \%$ gel under reducing conditions, followed by silver staining as described previously [3].

2.6. UV Spectrophotometry. The UV absorption characteristics of control and modified histone were recorded on UVvisible spectrophotometer (Biotek, model FLx800) between 200 and $400 \mathrm{~nm}$ using UV microtiter plates. The increase in absorbance (hyperchromicity) was calculated using the following formula:

$$
\text { Hyperchromicity }(\%)=\left(\frac{A_{\text {modified }}-A_{\text {control }}}{A_{\text {modified }}}\right) \times 100 \text {. }
$$

2.7. Fluorescence Study. Control and modified histones were subjected to fluorescence studies on spectrofluorophotometer (Hitachi, model F-2500). Fluorescence was measured at $25 \pm 0.1^{\circ} \mathrm{C}$ in cuvette of $1 \mathrm{~cm}$ pathlength, with slit width fixed at $10 \mathrm{~nm}$. Formation of AGE-chromophores on histone was measured by AGE-type fluorescence at 320/380, 335/385 nm $\left(\lambda_{\mathrm{ex}} / \lambda_{\mathrm{em}}\right)$. Increase in fluorescence intensity (FI) was calculated using the following formula:

$$
\% \text { Increase of } \mathrm{FI}=\left(\frac{\mathrm{FI}_{\text {modified }}-\mathrm{FI}_{\text {control }}}{\mathrm{FI}_{\text {modified }}}\right) \times 100 \text {. }
$$

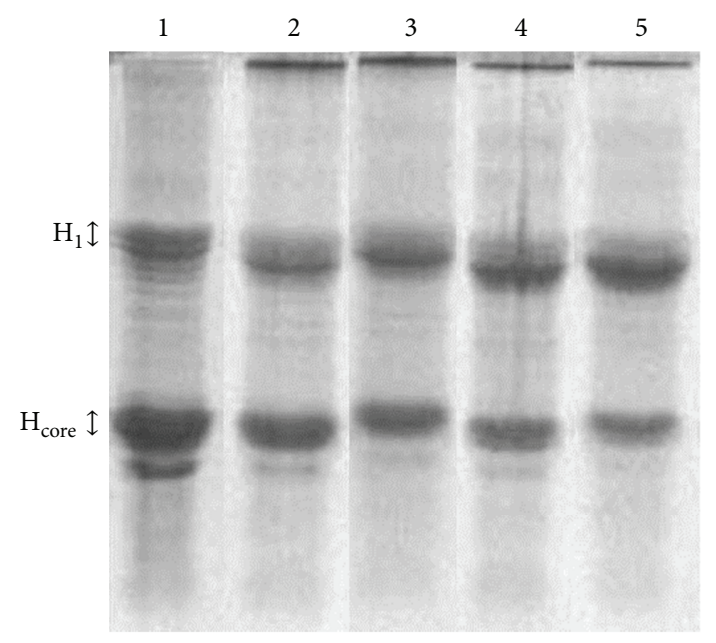

FIGURE 1: SDS-PAGE (15\%) of native histone (lane 1) and histone modified with 1 and $2 \mathrm{mM}$ methylglyoxal (lanes 2 and 3, resp.) and 1 and $2 \mathrm{mM}$ glyoxal (lanes 4 and 5, resp.). Electrophoresis was carried out for $3 \mathrm{~h}$ at 80 volts and the gel was visualized using silver staining.

2.8. FTIR Spectroscopy. The FTIR absorption spectra of the samples were recorded on Nicolet 5700 FTIR spectrometer (Thermo Corporation) in the range from 1500 to $1700 \mathrm{~cm}^{-1}$ with a nominal resolution of $4 \mathrm{~cm}^{-1}$. All measurements were carried out at room temperature. Automated spectra of control and modified histones were obtained from the subtraction spectra $[$ (control + buffer $)-($ buffer $)]$ and $[$ (control + modified + buffer $)-($ control + buffer $)]$.

2.9. Detection of Antibodies against Methylglyoxal-Modified Histone in Type 1 Diabetes Patients. Presence of antibodies against the modified histone in the sera of type 1 diabetes patients was evaluated by solid-phase enzyme immunoassay. Enzyme-linked immunosorbent assay (ELISA) was performed on polystyrene plates as described previously [10]. Absorbance $(A)$ was monitored at $410 \mathrm{~nm}$ on an automatic microplate reader and mean of duplicate readings for each sample was recorded. Results have been expressed as a mean of $A_{\text {test }}-A_{\text {control }}$.

\section{Results \& Discussion}

RCS-induced alteration in histone was examined by sodium dodecyl sulfate polyacrylamide gel electrophoresis (SDSPAGE) on $15 \%$ polyacrylamide gel after silver staining. The migration pattern of silver-stained bands during SDS-PAGE is shown in Figure 1. The pattern of native histone revealed sharp bands of linker and core fractions (lane 1) which underwent significant changes upon modification with 1 and $2 \mathrm{mM}$ methylglyoxal (lanes 2 and 3, resp.) and 1 and $2 \mathrm{mM}$ glyoxal (lanes 4 and 5, resp.). Both of the modified histones exhibited slightly higher-molecular-weight core histone fractions (lanes 3 and 5), having reduced mobility in the gel compared to the native ones. The modifier produced aggregation of histone molecules into high molecular weight 


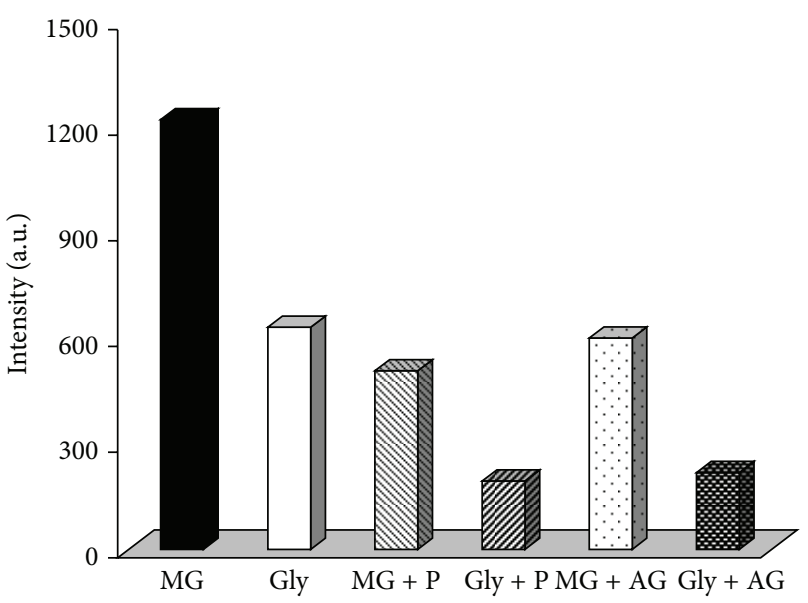

FIGURE 2: Fluorescence inhibition by penicillamine $(\mathrm{P})$ and aminoguanidine (AG) during incubation of histones with methylglyoxal (MG) and glyoxal (Gly).

polymers, bands of which were restricted to top of the stacking gel. A more extensive histone polymerization caused by methylglyoxal, with a $2 \mathrm{mM}$ concentration, showed that it was a slightly more effective protein cross-linker. Glycationmediated cross-linking of proteins is known to produce dimers and high-molecular-weight polymers having reduced mobility in electrophoresis [11].

Penicillamine and aminoguanidine used in the present study are potent carbonyl scavengers and exert a direct effect on RCS. When the scavengers $(3 \mathrm{mM})$ were present in the RCS-modified reaction mixture, the corresponding results were shown in Figure 2. They showed significant inhibitory effect on the fluorescence induced by both methylglyoxaland glyoxal-modified histones. There was quenching of $58 \%$ and $69 \%$ in fluorescence intensity of methylglyoxal- and glyoxal-modified histones by penicillamine while it was $51 \%$ and $65 \%$ by aminoguanidine. This study confirmed involvement of the RCS in glycoxidation of histones and indicate that methylglyoxal was a more effective modifier than glyoxal.

Histone modified with different concentrations of methylglyoxal was further characterized by spectral techniques. UV and fluorescence data of histone modified with methylglyoxal are summarized in Table 1 . Native histone had characteristic absorption peak at $206 \mathrm{~nm}$ due to its lysine content (Figure 3). Upon modification with methylglyoxal, increase in absorbance was recorded, extent of which was dependent on the modifier concentration. Modified histone samples also exhibited new broad peak at $320 \mathrm{~nm}$. AGE adducts of lysine and arginine residues in glycated proteins are determined by AGE-specific absorbance at $330 \mathrm{~nm}$ [12]. The hyperchromicity exhibited by histone, modified with 1 and $2 \mathrm{mM}$ methylglyoxal, were $41 \%$ and $76 \%$, respectively, at $320 \mathrm{~nm}$. The increase in absorbance and appearance of AGE-specific peak in histone modified with the RCS is an indication of structural changes in the histones.

AGE formation in methylglyoxal-modified histone led to an increase in fluorescence intensity, associated with shift in the emission maximum from $419 \mathrm{~nm}$ (native histone)
TABLE 1: UV and fluorescence data of native and methylglyoxal modified histones under identical experimental conditions.

\begin{tabular}{|c|c|c|c|}
\hline & $\begin{array}{l}\text { Native } \\
\text { histone }\end{array}$ & $\begin{array}{l}\text { Methylglyoxal- } \\
\text { modified } \\
\text { histone }\end{array}$ & Modification \\
\hline $\begin{array}{l}\text { UV absorbance } \\
\text { at } 320 \mathrm{~nm}^{\text {a }}\end{array}$ & 0.22 & 0.37 & $41.2 \%$ \\
\hline $\begin{array}{l}\text { UV absorbance } \\
\text { at } 320 \mathrm{~nm}^{\mathrm{b}}\end{array}$ & 0.22 & 0.76 & $76.2 \%$ \\
\hline $\begin{array}{l}\text { Fluorescence } \\
\text { intensity }^{\mathrm{a}} \\
(\text { Ex. } 320 \mathrm{~nm})\end{array}$ & $\begin{array}{c}222 \\
(\text { Em. } 419 \mathrm{~nm})\end{array}$ & $\begin{array}{c}335 \\
(\mathrm{Em} .413 \mathrm{~nm})\end{array}$ & $33.7 \%$ \\
\hline $\begin{array}{l}\text { Fluorescence } \\
\text { intensity } \\
(\text { Ex. } 320 \mathrm{~nm})\end{array}$ & $\begin{array}{c}222 \\
(\text { Em. } 419 \mathrm{~nm})\end{array}$ & $\begin{array}{c}1220 \\
(\mathrm{Em} .440 \mathrm{~nm})\end{array}$ & $81.7 \%$ \\
\hline
\end{tabular}

$\mathrm{a}$ and $\mathrm{b}$ represent 1 and $2 \mathrm{mM}$ concentrations, respectively, of the histone modifier.

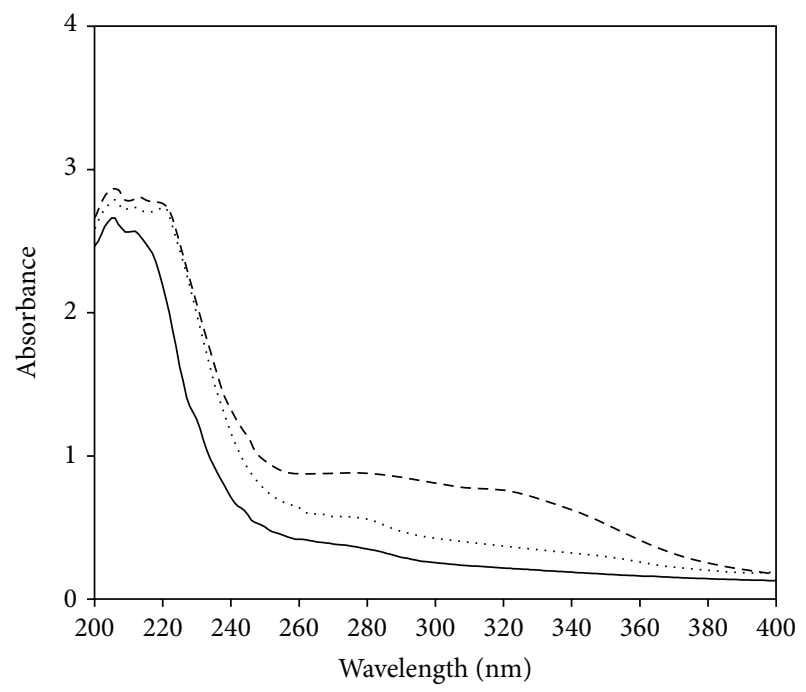

FIGURE 3: Absorption spectra of native histone (-) and histone modified with $1 \mathrm{mM}(\cdots)$ and $2 \mathrm{mM} \mathrm{(-})$ methylglyoxal.

to 413 and $440 \mathrm{~nm}$ in presence of 1 and $2 \mathrm{mM}$ methylglyoxal, respectively, upon excitation at $320 \mathrm{~nm}$ (Figure 4). The observed increase in intensity was $34 \%$ at $413 \mathrm{~nm}(1 \mathrm{mM}$ methylglyoxal) and $82 \%$ at $440 \mathrm{~nm}(2 \mathrm{mM}$ methylglyoxal). However, the intensity enhancement was $26 \%$ at $419 \mathrm{~nm}$ and $74 \%$ at $438 \mathrm{~nm}$ with 1 and $2 \mathrm{mM}$ methylglyoxal (data not shown), upon excitation at $335 \mathrm{~nm}$. This observation may be attributed to rise in the level of AGE adduct in histone induced by increasing concentration of RCS. The emission wavelength between $405-410 \mathrm{~nm}$ has been shown to reflect AGE structures of argpyrimidine and pentosidine [12].

The conformational changes in RCS-modified histone were determined by FTIR spectra (Figure 5). There was shift in position and intensity of amide bands with respect to native histone at $\mathrm{pH}$ 7.4. Amide I gives rise to infrared bands in the region between 1600 and $1700 \mathrm{~cm}^{-1}$ and is considered a sensitive probe to study secondary structures of proteins, namely, random coils, $\alpha$ helix, and $\beta$ sheets. The main spectral 


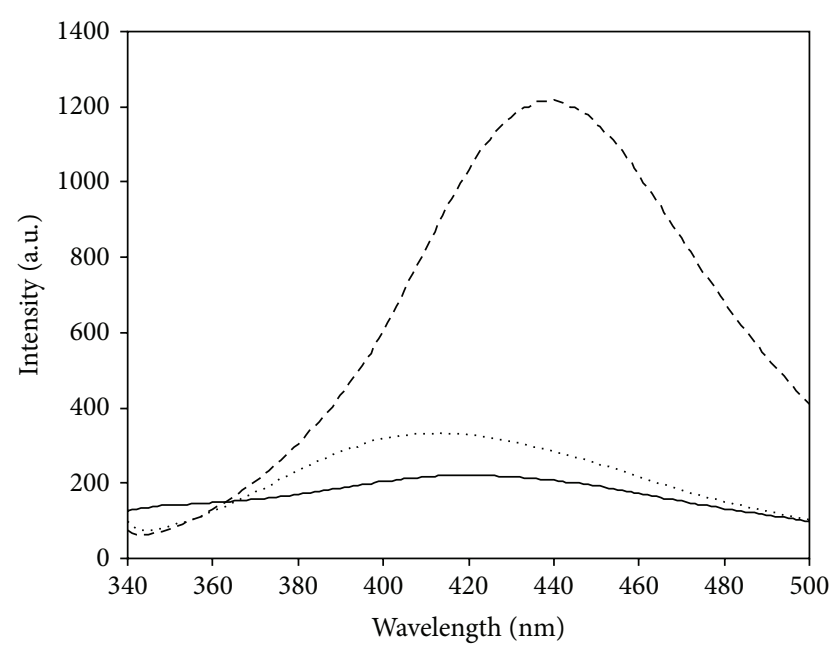

FIGURE 4: Fluorescence emission spectra of native histone $(-)$ and histone modified with $1 \mathrm{mM}(\cdots)$ and $2 \mathrm{mM}(--)$ methylglyoxal. Excitation, $320 \mathrm{~nm}$.

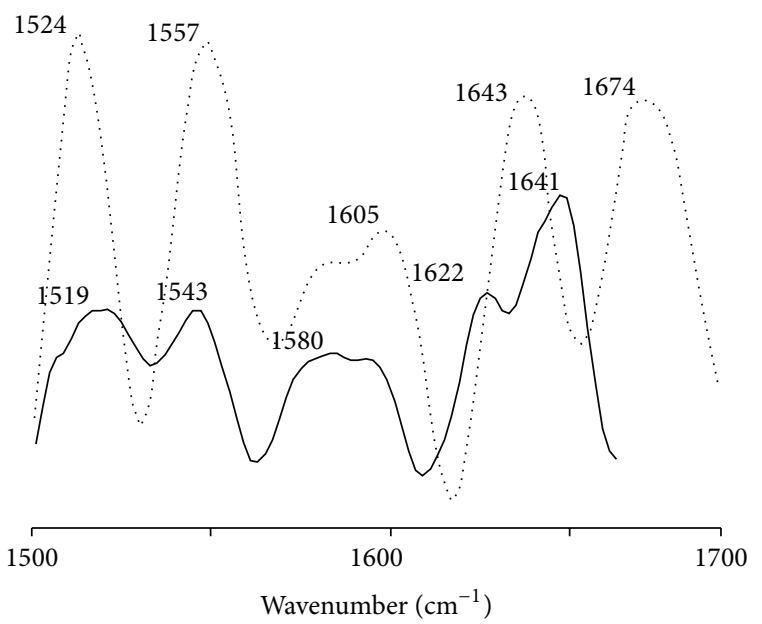

FIGURE 5: FTIR spectra of histone (-) modified with methylglyoxal $(\cdots)$.

features of native histone were characterized by an intense band at $1641 \mathrm{~cm}^{-1}$ and a weak one at $1622 \mathrm{~cm}^{-1}$ corresponding to $\alpha$ helix and pleated sheet structures, respectively. In contrast, histone modified with a $2 \mathrm{mM}$ of methylglyoxal showed distinct variations in both peak position and intensity, suggestive of changes in the histone structure upon modification. The bands at 1641 and $1622 \mathrm{~cm}^{-1}$ were shifted to 1643 and $1605 \mathrm{~cm}^{-1}$ in methylglyoxal-modified histone. The prominent and broad peak bands in the range of $1605-1610 \mathrm{~cm}^{-1}$ indicate a higher content of pleated structure in the modified histones whereas the appearance of a strong band in the range of $1670-1675 \mathrm{~cm}^{-1}$ in the modified histones corresponded to the presence of random form. A similar change in both peak position and intensity of histone modified with RCS appears in amide II bands in the region between 1500 and $1600 \mathrm{~cm}^{-1}$. The diagnostic amide I IR bands corresponding to native and modified histones are compiled in Table 2.
TABLE 2: Prominent FTIR amide I bands in secondary structure of histone modified with methylglyoxal (MG).

\begin{tabular}{lccc}
\hline & Random coil & $\begin{array}{c}\alpha \text { Helix } \\
\left(\text { in cm }^{-1}\right)\end{array}$ & $\beta$ Sheet \\
\hline Histone $^{\mathrm{n}}$ & - & 1641 & 1622 \\
MG-modified histone $^{\mathrm{a}}$ & 1674 & 1643 & 1605 \\
\hline
\end{tabular}

n: native histone.

a represents $2 \mathrm{mM}$ concentration of the histone modifiers.

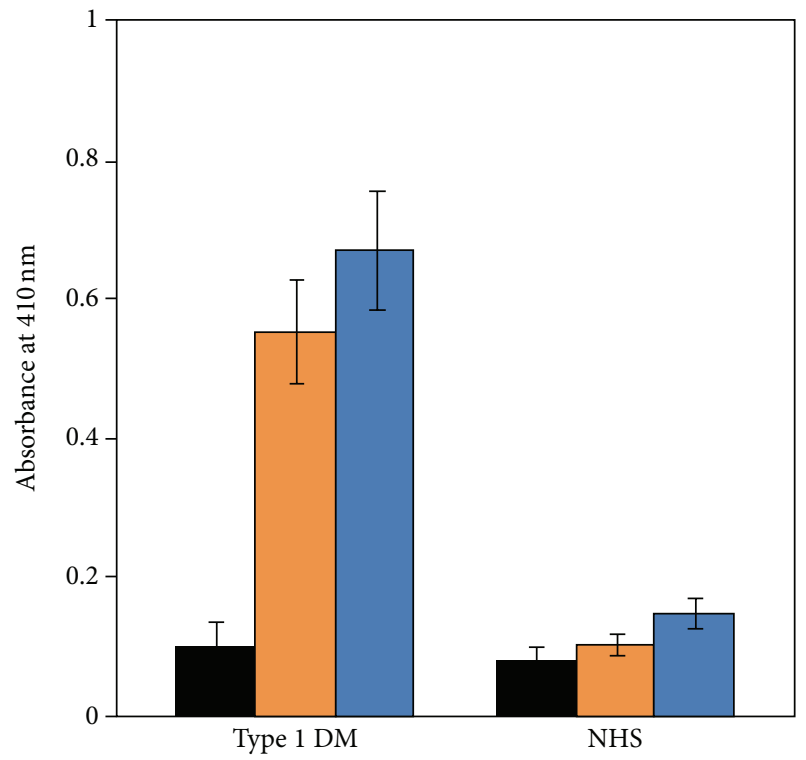

FIGURE 6: Direct binding ELISA of 1:100 diluted type 1 diabetes mellitus serum (type $1 \mathrm{DM}$ ) and normal human serum (NHS) samples to native histone (black square) and histone modified with $1 \mathrm{mM}$ (orange square) and $2 \mathrm{mM}$ (blue square) methylglyoxal.

We have determined role of the modified histone in type 1 diabetes. This study comprised 22 serum samples from the diseased patients while 11 samples were from healthy controls. Serum antibodies from diabetes patients showed appreciable binding to methylglyoxal-modified histone as compared to the native form at $1: 100$ serum dilution $(P<$ 0.001 ) in direct binding ELISA (Figure 6). Binding increased with rise in concentration of the modifier as revealed by absorbance studies based on ELISA. The average absorbances $( \pm \mathrm{SD})$ with the sera of type 1 diabetes patients binding to native histone and histone modified with 1 and $2 \mathrm{mM}$ methylglyoxal were $0.15 \pm 0.03,0.56 \pm 0.07$, and $0.67 \pm$ 0.08 , respectively. No appreciable binding was observed in normal subjects. We have found antibodies to AGE modified $\mathrm{IgG}$, a lysine-rich protein, in type 1 diabetes patients [13]. Another study has shown promising result towards detection of both lysine-derived and arginine-derived AGEs by the induced antibodies against AGE-modified BSA [14]. There is involvement of nonenzymatic glycosylation of proteins, specifically on lysine residues, in age-related diseases $[15,16]$. Recent studies have implicated lysine in inhibition of the glycation process both in vitro and in vivo $[17,18]$. 


\section{Conclusions}

The results reported here demonstrate that spectral analysis of methylglyoxal-modified histone provides a useful insight into the structural perturbation of lysine and arginine residues in histone and determines formation of AGE adducts in histone during the $24 \mathrm{~h}$ incubation of histone with methylglyoxal. Methylglyoxal-mediated histone glycation is also recognized by serum antibodies of type 1 diabetes patients. It has been revealed from our study that the RCS-modified histones might be a potential target for circulating autoantibodies in patients with type 1 diabetes mellitus and this target can be used as a predictive biomarker for controlling the disease complications.

\section{Conflict of Interests}

Authors of this paper have no direct financial relation with the commercial identities mentioned in the paper.

\section{Acknowledgment}

This research work was supported by a Grant (no. F.42/2006(BSR)/13-192/2008(BSR)) from UGC DS Kothari PostDoctoral Fellowship Scheme, India.

\section{References}

[1] J. W. Baynes and S. R. Thorpe, "Role of oxidative stress in diabetic complications: a new perspective on an old paradigm," Diabetes, vol. 48, no. 1, pp. 1-9, 1997.

[2] J. W. Baynes and S. R. Thorpe, "Glycoxidation and lipoxidation in atherogenesis," Free Radical Biology and Medicine, vol. 28, no. 12, pp. 1708-1716, 2000.

[3] M. J. Roberts, G. T. Wondrak, D. C. Laurean, M. K. Jacobson, and E. Jacobson, "DNA damage by carbonyl stress in human skin cells," Mutation Research, vol. 522, no. 1-2, pp. 45-56, 2003.

[4] D. Cervantes-Laurean, M. J. Roberts, E. L. Jacobson, and M. K. Jacobson, "Nuclear proteasome activation and degradation of carboxymethylated histones in human keratinocytes following glyoxal treatment," Free Radical Biology and Medicine, vol. 38, no. 6, pp. 786-795, 2005.

[5] A. Gugliucci and M. Bendayan, "Histones from diabetic rats contain increased levels of advanced glycation end products," Biochemical and Biophysical Research Communications, vol. 212, no. 1, pp. 56-62, 1995.

[6] N. A. Ansari, M. Moinuddin, K. Alam, and A. Ali, "Preferential recognition of Amadori-rich lysine residues by serum antibodies in diabetes mellitus: role of protein glycation in the disease process," Human Immunology, vol. 70, no. 6, pp. 417-424, 2009.

[7] S. Pashikanti, G. A. Boissonneault, and D. Cervantes-Laurean, "Ex vivo detection of histone $\mathrm{H} 1$ modified with advanced glycation end products," Free Radical Biology and Medicine, vol. 50, no. 10, pp. 1410-1416, 2011.

[8] A. Gugliucci, D. H. M. Bastos, J. Schulze, and M. F. F. Souza, "Caffeic and chlorogenic acids in Ilex paraguariensis extracts are the main inhibitors of AGE generation by methylglyoxal in model proteins," Fitoterapia, vol. 80, no. 6, pp. 339-344, 2009.

[9] A. Gugliucci and T. Menini, "The polyamines spermine and spermidine protect proteins from structural and functional damage by AGE precursors: a new role for old molecules?" Life Sciences, vol. 72, no. 23, pp. 2603-2616, 2003.

[10] R. Ali and K. Alam, "Evaluation of antibodies against oxygen free radical-modified DNA by ELISA," in Methods in Molecular Biology: Oxidative Stress Biomarkers and Antioxidants Protocols, D. Armstrong, Ed., pp. 171-181, Humana Press, New Jersey, NJ, USA, 2002.

[11] H. Talasz, S. Wasserer, and B. Puschendorf, "Nonenzymatic glycation of histones in vitro and in vivo," Journal of Cellular Biochemistry, vol. 85, no. 1, pp. 24-34, 2002.

[12] A. Schmitt, J. Schmitt, G. Münch, and J. Gasic-Milencovic, "Characterization of advanced glycation end products for biochemical studies: side chain modifications and fluorescence characteristics," Analytical Biochemistry, vol. 338, no. 2, pp. 201215, 2005.

[13] Z. Rasheed, L. Kumar, S. Abbas, I. Prasad, N. A. Ansari, and R. Ahmad, "Advanced glycation end-products (AGEs) damaged IgG, a target for circulating autoantibodies in patients with type 1 diabetes mellitus," Open Glycoscience, vol. 2, pp. 1-8, 2009.

[14] Y. Choi and S. Lim, "Characterization of anti-advanced glycation end product antibodies to nonenzymatically lysinederived and arginine-derived glycated products," Journal of Immunoassay and Immunochemistry, vol. 30, no. 4, pp. 386-399, 2009.

[15] N. A. Ansari and Z. Rasheed, "Non-enzymatic glycation of proteins: from diabetes to cancer," Biochemistry $B$, vol. 3 , no. 4 , pp. 335-342, 2009.

[16] N. A. Ansari, M. Moinuddin, and R. Ali, "Glycated lysine residues: a marker for non-enzymatic protein glycation in agerelated diseases," Disease Markers, vol. 30, no. 6, pp. 317-324, 2011.

[17] H. M. Sims, A. L. Birdwell, K. E. OReilley, A. Bwashi, and B. D. Wing, "Inhibition of protein glycation with varying concentrations of lysine," The FASEB Journal, vol. 22, 1123. 15, 2008.

[18] A. Jafarnejad, S. Z. Bathaie, M. Nakhjavani, M. Z. Hassan, and S. Banasadegh, "The improvement effect of L-Lys as a chemical chaperone on STZ-induced diabetic rats, protein structure and function," Diabetes/Metabolism Research and Reviews, vol. 24, no. 1, pp. 64-73, 2008. 

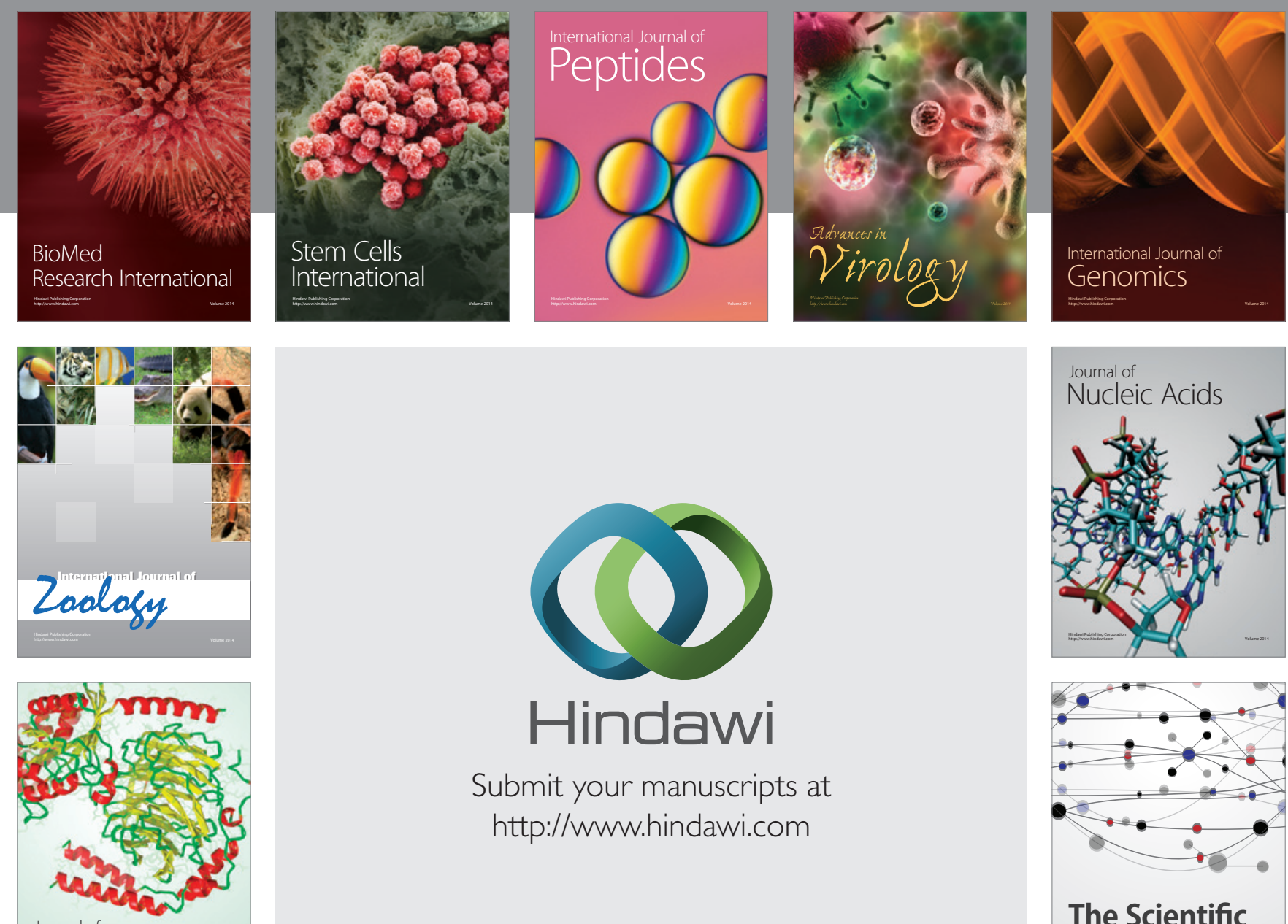

Submit your manuscripts at

http://www.hindawi.com

Journal of
Signal Transduction
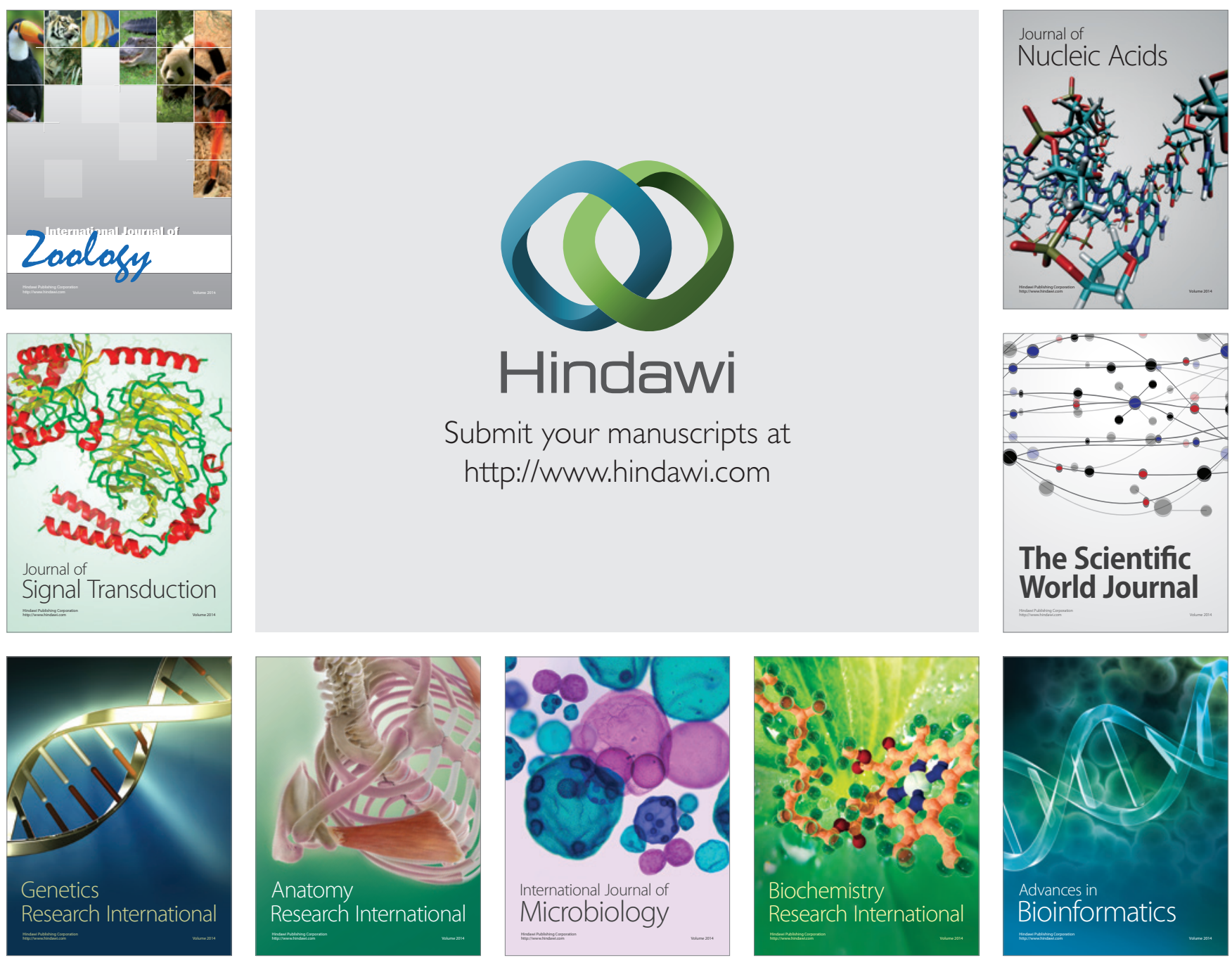

The Scientific World Journal
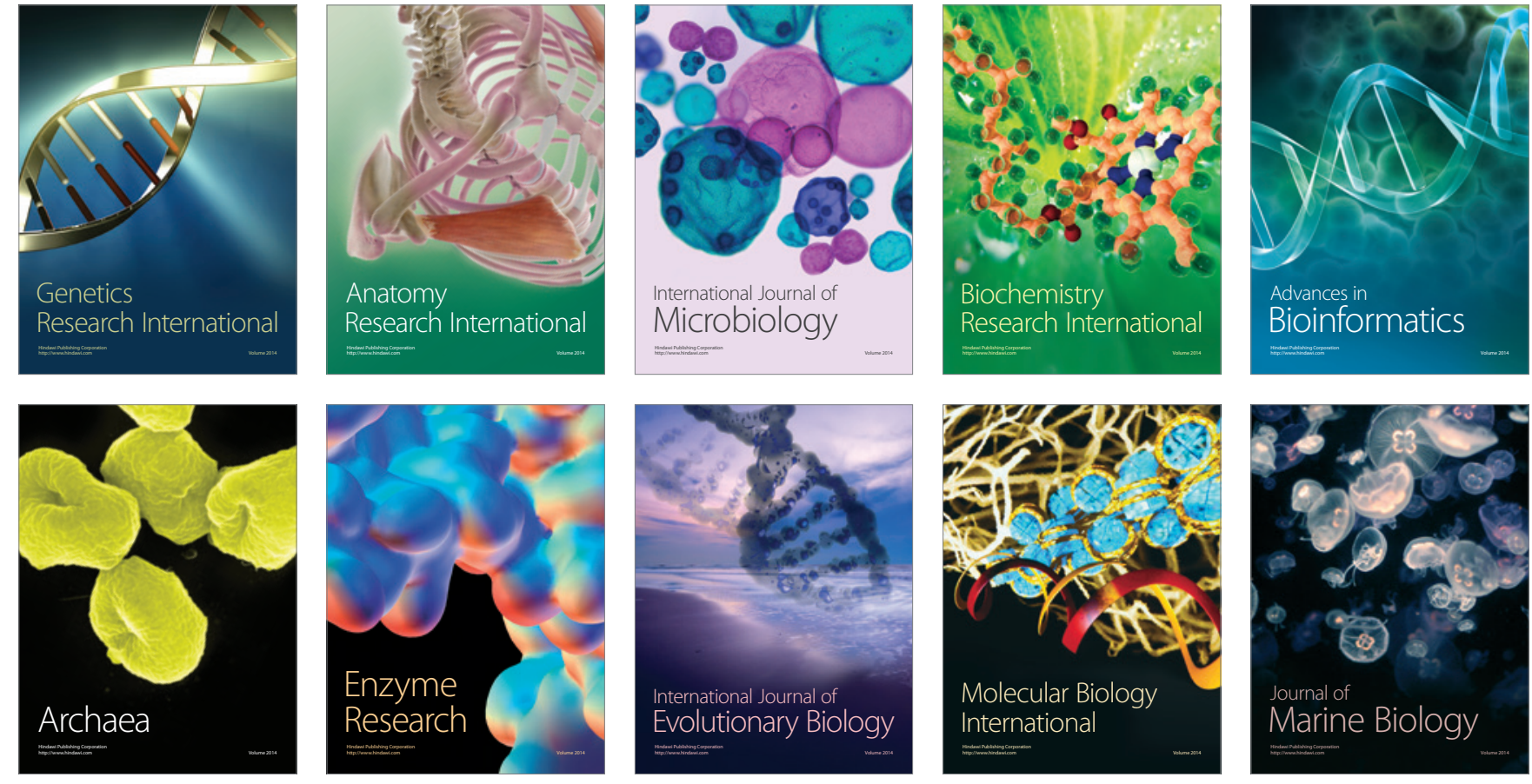